British Journal of Nutrition (2022), 128, 1689-1699

doi: $10.1017 /$ S000711452100461X

(C) The Author(s), 2021. Published by Cambridge University Press on behalf of The Nutrition Society. This is an Open Access article, distributed under the terms of the Creative Commons Attribution-NonCommercial-NoDerivatives licence (https://creativecommons.org/licenses/by-nc-nd/4.0/), which permits non-commercial re-use, distribution, and reproduction in any medium, provided the original work is unaltered and is properly cited. The written permission of Cambridge University Press must be obtained for commercial re-use or in order to create a derivative work.

\title{
Dietary calcium to phosphorus ratio affects postprandial phosphorus concentrations in feline plasma
}

\author{
Jennifer Carolyn Coltherd*, Ruth Staunton, Alison Colyer, Matthew Gilham, John Rawlings, \\ Janet E. Alexander, Darren W. Logan, Richard Butterwick, Phillip Watson and Anne Marie Bakke \\ Waltham Petcare Science Institute, Waltham-on-the-Wolds, Leicestershire, UK \\ (Submitted 18 December 2020 - Final revision received 8 November 2021 - Accepted 15 November 2021 - First published online 18 November 2021)
}

\section{Abstract}

The impact of dietary phosphorus on chronic renal disease in cats, humans and other species is receiving increasing attention. As Ca and $\mathrm{P}$ metabolism are linked, the ratio of $\mathrm{Ca}: \mathrm{P}$ is an important factor for consideration when formulating diets for cats and other animals. Here, we describe a fully randomised crossover study including twenty-four healthy, neutered adult cats, investigating postprandial responses in plasma $\mathrm{P}$, ionised $\mathrm{Ca}$ and parathyroid hormone (PTH) following one meal ( $50 \%$ of individual metabolic energy requirement) of each of six experimental diets. Diets were formulated to provide P at either 0.75 or $1.5 \mathrm{~g} / 1000 \mathrm{kcal}(4184 \mathrm{~kJ})$ from the soluble phosphorus salt sodium tripolyphosphate (STPP, $\mathrm{Na}_{5} \mathrm{P}_{3} \mathrm{O}_{10}$ ), variable levels of organic $\mathrm{Ca}$ and $\mathrm{P}$ sources, and an intended total Ca:P of about 1·0, 1.5 or $2 \cdot 0$. For each experimental diet, baseline fasted blood samples were collected prior to the meal, and serial blood samples collected hourly for $6 \mathrm{~h}$ thereafter. For all diets, a significant increase from baseline was observed at $120 \mathrm{~min}$ in plasma PTH $(P<0 \cdot 001)$. The diet containing the highest STPP inclusion level and lowest Ca:P induced the highest peaks in postprandial plasma P and PTH levels ( $1.8 \mathrm{mmol} / \mathrm{l}$ and $27.2 \mathrm{pg} / \mathrm{ml}$, respectively), and the longest duration of concentrations raised above baseline were observed at $3 \mathrm{~h}$ for P and $6 \mathrm{~h}$ for PTH. Data indicate that Ca:P modulates postprandial plasma P and PTH. Therefore, when formulating diets containing soluble P salts for cats, increasing the Ca:P ratio should be considered.

Key words: Plasma phosphorus kinetics: Cats: PTH

Chronic kidney disease is a common disease in adult and elderly cats $^{(1)}$. Dietary phosphorus $(\mathrm{P})$ concentrations have received increased focus as a contributing factor in accelerating kidney disease ${ }^{(2,3)}$. Studies in cats investigating postprandial appearance of $\mathrm{P}$ in plasma showed that diets incorporating highly soluble forms of $\mathrm{P}$ induced dose-dependent increases in $\mathrm{P}$ concentration as well as the $\mathrm{Ca}$ and $\mathrm{P}$ regulatory parathyroid hormone $(\mathrm{PTH})^{(4)}$. At the highest inclusion of highly soluble $\mathrm{P}$ tested, there was also a significant reduction in whole blood ionised $\mathrm{Ca}$ (iCa) ${ }^{(4)}$. Although the acute exposure studies were not designed to assess the safety of a diet, the observations summarised above are indicative of being aetiological factors in the development of renal changes observed following longer-term dietary exposure by Alexander et $a l^{(2)}$. Studies utilising cats have shown that sustained increases in either plasma P or PTH, respectively, may also have long-term consequences on $\mathrm{Ca}$ and $\mathrm{P}$ homoeostasis ${ }^{(5,6)}$. The ability to reduce absorption of $\mathrm{P}$ from the intestine is therefore desirable in any species from humans to felines ${ }^{(6,7)}$. Two strategies have been employed previously from a dietary perspective: limiting the inclusion level of highly soluble forms of $\mathrm{P}^{(8,9)}$ and/or the manipulation of other minerals to modulate the availability of $\mathrm{P}^{(10)}$.

The bioavailability of dietary $\mathrm{P}$ is not only influenced by the $\mathrm{P}$ source and content of the diet but also by the Ca:P ratio, with an increase from around 1:1 to nearly $2: 1$ reducing $\mathrm{P}$ digestibility and urinary $\mathrm{P}$ excretion ${ }^{(11-15)}$. Currently, European regulatory body FEDIAF recommends Ca:P between 1:1 and 2:1 for feline adult maintenance diets ${ }^{(16)}$. The mechanism behind the reduction in $\mathrm{P}$ bioavailability with increased dietary $\mathrm{Ca}: \mathrm{P}$ is thought to be due to the formation of insoluble, and hence non-bioavailable, $\mathrm{Ca}-\mathrm{Mg}-\mathrm{P}$ complexes in the intestinal tract when $\mathrm{Ca}$ availability is increased ${ }^{(15,17)}$. Similarly, insoluble complex formation is also likely to be the reason that increasing dietary $\mathrm{Mg}$ content has also been shown to decrease $\mathrm{P}$ absorption and hence urinary P concentration ${ }^{(18)}$. The solubility of the Ca source in the diet is also important in ensuring its availability to form these insoluble complexes and to bind $\mathrm{P}^{(14)}$.

Data reported by Coltherd et $a l^{(4)}$ indicated that despite remarkably similar total and added inorganic $\mathrm{P}$ inclusions, postprandial plasma P returned to baseline more quickly (within $3 \mathrm{~h}$ )

Abbreviations: iCa, ionised $\mathrm{Ca}$; PTH, parathyroid hormone; STPP, sodium tripolyphosphate.

* Corresponding author: Jennifer Carolyn Coltherd, email: jen.coltherd@effem.com 
when cats were fed a diet with a Ca:P $>1$ compared to $\mathrm{Ca}: \mathrm{P}<1$. This suggested that there might be an effect of $\mathrm{Ca}$ :P on the blunting of postprandial plasma $\mathrm{P}$ and $\mathrm{PTH}$ responses. However, there were other confounding factors within the diets used; therefore, any conclusions were tentative ${ }^{(4)}$. Thus, the aim of the current study was to systematically investigate the effect of three levels of total dietary Ca:P - low of about 1.0 , moderate of about 1.5 and high of about 2.0 - in diets supplemented with a high $(1.5 \mathrm{~g} \mathrm{P} / 1000 \mathrm{kcal}, 4184 \mathrm{~kJ})$ or low $(0.75 \mathrm{~g} \mathrm{P} / 1000 \mathrm{kcal}$, $4184 \mathrm{~kJ})$ level of inorganic $\mathrm{P}$ from sodium tripolyphosphate (STPP, $\mathrm{Na}_{5} \mathrm{P}_{3} \mathrm{O}_{10}$ ) on postprandial plasma $\mathrm{P}, \mathrm{iCa}$ and $\mathrm{PTH}$.

\section{Materials and methods}

The research protocol was reviewed and approved by the Waltham Animal Welfare and Ethical Review Body and carried out under the authority of the revised Animals (Scientific Procedures) Act 1986 incorporating EU Directive 2010/63. Cats were extensively trained for and habituated to all procedures. A fully randomised six-diet crossover study was performed with twenty-four neutered adult domestic shorthair cats, each cat acting as its' own control, as previously described $^{(4)}$. Briefly, the study comprised collection of baseline blood samples from the cats in the fasted state ( $>18 \mathrm{~h}$ ), a single 20-min meal exposure to each test diet comprising $50 \%$ of the individuals' daily metabolisable energy requirement, a pattern to which the cats were habituated to, and subsequent hourly blood collection via a cephalic catheter for monitoring of the postprandial plasma levels of $\mathrm{P}, \mathrm{iCa}$ and PTH for $6 \mathrm{~h}$ post-ingestion. Metabolisable energy requirement was calculated as $77.6 \times$ Body Weight ${ }^{0.711} \mathrm{kcal}(4 \cdot 184 \mathrm{~kJ})$ per d. The diets offered were blinded to all personnel involved in feeding, sampling the cats and during all sample analysis. Cats were split into six groups of four for sampling. A minimum of $10 \mathrm{~d}$ (no more than $14 \mathrm{~d}$ ) was scheduled between exposures, during which cats were fed a rotation of complete and balanced commercial diets from a range of manufacturers. The rotation coupled with the randomisation of the experimental diets was intended to minimise any increased variability by removing order effects of diets. A minimum of $10 \mathrm{~d}$ between samples were implemented for welfare reasons. Our pilot data showed no effects on plasma P, PTH and whole blood iCa of a 7-d break, regardless of diet order, between sampling days ${ }^{(4)}$.

\section{Animals}

For details of the cats and diet intakes, see Table 1 . To ensure suitability for the study, the cats underwent a pre-study health assessment, including a physical examination by a registered Veterinary Surgeon and haematological, plasma biochemical and urine analysis to confirm the absence of underlying conditions. Cats were group housed in social rooms under routine husbandry conditions. On the day of sampling, cats were allowed to return to their social rooms and monitored closely to ensure the cats' welfare (i.e. not pulling out the catheter). Throughout the study, commercial rotation (wet and dry format) diets were offered in amounts required to maintain an ideal body weight and body condition score, assessed according to a 9-point scale. These were used to calculate individual metabolisable energy requirement ${ }^{(19)}$. Deionised water was available ad libitum during the sampling days.

\section{Diets}

Experimental wet format diets were specifically formulated and manufactured using standard commercial raw materials by Mars Petcare Inc.. Poultry necks, pork liver, meat organs, blood plasma, potassium chloride, choline chloride, xylose, xantham gum, maize starch, and vitamin, amino acid and mineral mixes were the raw materials used for all experimental diets. Poultry necks, pork liver, meat organs, STPP and calcium carbonate were adjusted or added to the formulation to achieve the desired nutritional profiles. Nutritional composition was confirmed through analyses carried out at Eurofins Ltd, Wolverhampton, UK, utilising AOAC official methods of analyses (see Table 2 for details). STPP was used as the main source of inorganic P. Additional inorganic $\mathrm{P}$ present in the raw materials accounted for less than $2.6 \%$ of the total P from STPP added and was therefore negligible. The diets incorporating high STPP (A-C), contributing $1.5 \mathrm{~g} \mathrm{P} / 1000 \mathrm{kcal}(4184 \mathrm{~kJ})$, were formulated from the same base recipe, whereby calcium carbonate content was manipulated to achieve the desired total $\mathrm{Ca}: \mathrm{P}$ ratios of about $1 \cdot 0,1 \cdot 5$ and $2 \cdot 0$. The second base diet, in which the levels of the same ingredients used for diets A-C were adjusted, was formulated to contain low STPP (D-F) contributing $0.75 \mathrm{~g} \mathrm{P} / 1000 \mathrm{kcal}$ (4184 kJ). Although added P levels were controlled, variability in raw materials resulted in slightly higher total $\mathrm{P}$ concentrations in diets $\mathrm{E}$ and $\mathrm{F}$, and $\mathrm{Ca}: \mathrm{P}$ ratios of $0.95,1.62$ and 2.03 for diets $\mathrm{A}-\mathrm{C}$ and 1.11, 1.70 and 2.04 for diets D-F (Table 2). Diets were randomised to prevent any order bias.

\section{Blood sampling}

Following an overnight fast ( $>18 \mathrm{~h}$ ), topical local anaesthetic (1 ml EMLA ${ }^{\mathrm{TM}}$ cream $5 \%$ AstraZeneca UK Limited) was applied and a cephalic catheter positioned, which remained in place for the duration of the sampling period on each sampling day. To maintain patency, a $0 \cdot 2-\mathrm{ml}$ heparin flush and discard was performed before each collection with a $2-\mathrm{ml}$ saline flush thereafter. A fasted blood sample $(1.7 \mathrm{ml})$ was collected to provide a baseline, with further samples taken at 60 min intervals $(0.5 \mathrm{ml}$ at 1,3 and $5 \mathrm{~h}$ and $1.5 \mathrm{ml}$ at 2, 4 and $6 \mathrm{~h}$ ) following the meal up to and including, $6 \mathrm{~h}$ post-feeding.

\section{Blood sample processing and analysis}

Blood samples $(0.5 \mathrm{ml})$ were collected into lithium heparin tubes (Sarstedt Inc.) and placed on ice until analysis was performed (within 60 min of sampling). iCa was measured in whole blood via an ion-selective electrode using a Stat Profile Prime Veterinary Critical Care Analyser (Nova Biomedicals UK). Performance of the instrument was verified by the analysis of the manufacturers' tri-level quality control material before and after the sample measurement. Plasma was isolated by centrifugation at $2000 \times \mathrm{g}$ for $10 \mathrm{~min}$ at $4^{\circ} \mathrm{C}$. Phosphorus, in the form of orthophosphate, was photometrically quantified in non-ashed plasma using an AU480 clinical chemistry analyser (Beckman 
Table 1. Description of the cats and experimental diet intakes. The values are means and the respective ranges

\begin{tabular}{|c|c|c|}
\hline Age (years): & $5 \cdot 14$ & $2 \cdot 7-7.9$ \\
\hline Sex & 17 males, 7 females & \\
\hline Body weight $(\mathrm{kg})$ & 4.45 & $3 \cdot 34-5 \cdot 62$ \\
\hline $100 \%$ experimental meal ${ }^{*}$ consumed (number of cats) & A: 17; B:17; C:16; D:19; E:16; F:18 & \\
\hline When whole experimental meal ${ }^{\star}$ not consumed, intake (\%) & $\begin{array}{l}\text { A: } 74.6 \text { (38.1-94.5); B: } 76.7(41.7-99.2) ; C: 76.6(40.7-99.3) ; \\
\text { D: } 67.6(44.2-99.5) ; \text { E: } 84.2(63.2-97.9) \text { \& F: } 79.5(46.1-95.0)\end{array}$ & \\
\hline
\end{tabular}

* Experimental meal $=50 \%$ of the daily metabolisable energy requirement.

Table 2. Nutrient composition of the experimental diets. Units are $\mathrm{g} / 1000 \mathrm{kcal}(4184 \mathrm{~kJ})$ metabolisable energy unless otherwise stated

\begin{tabular}{|c|c|c|c|c|c|c|}
\hline Diet & $A$ & B & C & D & $E$ & $\mathrm{~F}^{\star}$ \\
\hline Total P & 3.73 & $3 \cdot 71$ & $3 \cdot 84$ & 3.63 & 4.40 & 4.58 \\
\hline Added P† & 1.50 & 1.50 & 1.50 & 0.75 & 0.75 & 0.75 \\
\hline $\mathrm{Ca}$ & 3.55 & $6 \cdot 02$ & $7 \cdot 78$ & 4.03 & 7.49 & $9 \cdot 32$ \\
\hline Ca:P‡ & 0.95 & 1.62 & 2.03 & $1 \cdot 11$ & $1 \cdot 70$ & 2.04 \\
\hline $\mathrm{Na}$ & $2 \cdot 73$ & $2 \cdot 51$ & 2.66 & $1 \cdot 78$ & 1.94 & 1.87 \\
\hline $\mathrm{Mg}$ & 0.16 & 0.17 & 0.18 & 0.18 & 0.21 & 0.22 \\
\hline $\mathrm{K}$ & 3.57 & 3.50 & 3.68 & 3.32 & 3.50 & 3.25 \\
\hline $\mathrm{Cl}$ & 2.87 & 2.62 & 2.72 & 2.60 & 2.65 & 3.56 \\
\hline Vitamin $D_{3}(\mathrm{IU} / 1000 \mathrm{kcal}[4184 \mathrm{~kJ}])$ & $452 \cdot 39$ & $367 \cdot 16$ & $383 \cdot 81$ & 318.73 & $401 \cdot 17$ & $382 \cdot 12$ \\
\hline Protein & $121 \cdot 37$ & $128 \cdot 63$ & $125 \cdot 78$ & $131 \cdot 39$ & $136 \cdot 51$ & $136 \cdot 88$ \\
\hline Fat & 50.57 & $47 \cdot 46$ & $46 \cdot 68$ & 45.53 & 45.97 & 48.48 \\
\hline Ash & 25.97 & $27 \cdot 47$ & 32.42 & $22 \cdot 12$ & $30 \cdot 64$ & $35 \cdot 65$ \\
\hline Crude fibre & 2.73 & 3.75 & 2.59 & 3.90 & 6.96 & $14 \cdot 26$ \\
\hline Moisture (g/100 g) & 83.87 & 81.90 & $82 \cdot 20$ & 82.50 & $83 \cdot 20$ & $82 \cdot 80$ \\
\hline PME§ (kcal/100 g) & $73 \cdot 20$ & $80 \cdot 10$ & $77 \cdot 10$ & $76 \cdot 90$ & 71.80 & $70 \cdot 10$ \\
\hline Food base excessll (mEq/kg) & 29.66 & $133 \cdot 22$ & $201 \cdot 12$ & $18 \cdot 76$ & $121 \cdot 53$ & 143.58 \\
\hline
\end{tabular}

IU, international units; PME, predicted metabolisable energy.

* Suspected analytical error for crude fibre has likely led to an underestimation of PME and an overestimation of $\mathrm{g} / 1000 \mathrm{kcal}(4184 \mathrm{~kJ})$ values.

$\dagger$ Added $\mathrm{P}$ represents the target inclusion level of STPP, sodium tripolyphosphate $\mathrm{Na}_{5} \mathrm{P}_{3} \mathrm{O}_{10}$

$\ddagger$ Ca: $P$ ratio.

$\S$ Calculated by proximate analysis to PME according to NRC 2006 ${ }^{(5)} .1 \mathrm{kcal}=4.184 \mathrm{~kJ}$,

II Food base excess calculated from methionine and cysteine according to Jeremias et al. on a per $\mathrm{kg}$ food basis ${ }^{(41)}$.

Coulter (UK) Ltd) according to the manufacturer's instructions, and concentrations reported in $\mathrm{mmol} / \mathrm{l}$. To confirm acceptable instrument performance, the manufacturer's bi-level quality control material was analysed before, during and after the sampling period.

Internal fasted normal ranges for plasma $\mathrm{P}$ were $0 \cdot 9-2 \cdot 2$ $\mathrm{mmol} / \mathrm{l}$ and for whole blood iCa were $1.19-1.33 \mathrm{mmol} / \mathrm{l}$. Cats are classed as clinically hypercalcaemic when whole blood iCa is above $1.6 \mathrm{~g} \mathrm{mmol} / \mathrm{l}^{(20)}$.

Determination of plasma PTH concentration was performed at the Royal Veterinary College, London (UK). Blood samples (1 $\mathrm{ml}$ ) were collected in EDTA containing tubes (Sarstedt Inc.), and plasma prepared by centrifugation at $2000 \times \mathrm{g}$ for $10 \mathrm{~min}$ at $4^{\circ} \mathrm{C}$ before being stored at $-80^{\circ} \mathrm{C}$ until analysis. PTH concentrations were measured using a RIA (Scantibodies Laboratory, Inc.) according to the manufacturer recommendations. This assay measures human intact PTH and has previously been validated for use with feline samples, reference range $2 \cdot 9-26 \cdot 3 \mathrm{pg} / \mathrm{ml}^{(21,22)}$.

\section{Statistical powering}

Sample size analyses were performed to determine the number of cats needed in a crossover study design with six diets, to have $>80 \%$ power to detect $20 \%$ change in plasma P levels over seven time points. Twenty-one cats were required, and three extra cats were added to ensure full power was maintained in the event of cats being unable to complete the full six-diet exposure. Plasma P levels from a pilot study ${ }^{(4)}$ were used to estimate the between cat variability and within diet within cat variability. Data were then simulated (1000 for each scenario) according to these variability estimates and by inducing a difference for one diet at one time point. The power analysis was performed, as per the postprandial pilot data statistical analysis (given below). The power was estimated by the percentage of simulations where all comparisons relative to the mean that was changed were significant, at the overall family-wise error rate of $5 \%$.

\section{Statistical analysis}

For each diet, postprandial plasma P (primary measure), iCa and PTH concentrations were analysed using linear mixed effects models, with time nested in diet nested in animal as the random effects, and diet, time point and their interaction as the categorical fixed effects. Plasma P and PTH concentrations were log10 transformed prior to analyses where increasing variation in residuals with increasing value was observed. At some time points, 
data were missing due to non-compliant cat behaviour, the catheter becoming unviable or failure of laboratory equipment. However, the restricted maximum likelihood method of analysis was used to account for this and assumed these values were missing at random. Comparisons were made, using a family-wise adjusted $5 \%$ level for each measure, between diets at each time point and between baseline to each subsequent postprandial time point for each diet. Comparisons were made within STPP dietary inclusion level (A $v . \mathrm{B} v . \mathrm{C}$ and $\mathrm{D} v$. E $v$. F) and within Ca:P level (A $v$. D, B $v$. E, C $v$. F). Accordingly, means, difference between means (or fold change on $\log _{10}$ transformed data) were reported with $95 \%$ family-wise CI. Additionally, for each cat after each diet, the plasma $\mathrm{P}$ concentration at baseline was subtracted from all subsequent time points, and the trapezium rule used to calculate the AUC in h.mmol. l $^{-1}$. Separate linear mixed effects models were fit for each diet exposure with AUC as the response. Distributional assumptions were assessed by visual inspection of the residuals and were deemed to be upheld for all models. The fixed effect for each model was diet and the random effect was diet nested in animal. From each model, mean AUC with $95 \%$ CI are reported for all diets. Comparisons between diets are reported as differences with $95 \% \mathrm{CI}$ and $P$-values adjusted to account for multiple comparisons.

Analyses were performed in statistical software R v3.3.3 $3^{(23)}$ using libraries $l m e 4^{(24)}$ for linear mixed effects models, multcomp $p^{(25)}$ for simultaneous inference and ggplot $2^{(26)}$ for data visualisation.

\section{Results}

The results describe means by dietary group, not individual cat data, so that if significant changes are observed they can be attributed to the meal and not individual variability (see supplementary table for means and $95 \% \mathrm{CI}$ ).

One cat was below the reference range for fasted plasma $\mathrm{P}$ on three occasions $(\geq 0.83 \mathrm{mmol} / \mathrm{l})$ and no cats were above the reference range for fasted plasma PTH $(26 \cdot 3 \mathrm{pg} / \mathrm{ml})$. No cats had fasted total $\mathrm{Ca}$ concentrations above the reference range; however, iCa was more variable. No cats had a fasted whole blood $\mathrm{iCa}$ at a concentration regarded as clinically hypercalcaemic $(>1.6 \mathrm{mmol} / \mathrm{l})^{(20)}$, whilst twelve cats showed fasted whole blood iCa above the $1.33 \mathrm{mmol} / \mathrm{l}$ reference range maximum (mean $1.36 \mathrm{mmol} / \mathrm{l}$; range $1.34-1.46 \mathrm{mmol} / \mathrm{l}$ ).

Table 1 contains description of the cat population and intakes. Twenty-one cats had complete six-diet crossover datasets, while there was missing data for one cat each for diets A, B and $\mathrm{C}$ due to undesirable behaviours on the sample day.

Results of dietary analysis indicated that targets for dietary $\mathrm{P}$ and $\mathrm{Ca}: \mathrm{P}$ were within tolerance levels (Table 2). The raw ingredients used to manufacture the experimental diets were kept consistent across all diets in order to maintain consistency of nutrients, and the crude fibre result for diet $\mathrm{F}$ was therefore unexpected and may be due to analytical variability.

Effect of dietary inorganic phosphorus inclusion and calcium to phosphorus ratio on postprandial plasma phosphorus

Postprandial responses in plasma $\mathrm{P}$ were increased, compared with baseline (fasted state), from $120 \mathrm{~min}$ post-feeding experimental diets A-D to cats $(P<0 \cdot 001 ;$ Fig. 1$)$. These increases in postprandial plasma $P$ reached the maxima from baseline at $180 \mathrm{~min}$ in the cats fed the diet subsets containing low Ca:P (A and D) and returned to baseline at $300 \mathrm{~min}$. Cats fed the mid to high (B and C, respectively) dietary Ca:P had a maxima postprandial plasma $\mathrm{P}$ concentration at $120 \mathrm{~min}$ which returned to baseline at $240 \min (P<0.001$; Fig. 1). Peak plasma $\mathrm{P}$ concentrations of $1.80,1.53$ and $1.50 \mathrm{mmol} / \mathrm{l}$ were observed for diets $\mathrm{A}, \mathrm{B}$ and $\mathrm{C}$, respectively, compared with $1.54,1.28$ and $1.16 \mathrm{mmol} / \mathrm{l}$ for diets $\mathrm{D}, \mathrm{E}$ and $\mathrm{F}$, respectively. A significant difference between the plasma $P$-values from 120 min onwards when fed diets $\mathrm{B}$ and $\mathrm{C}$ was not found $(P>0.05)$. Significant reductions in plasma $\mathrm{P}$ concentrations from baseline were observed in cats fed diets $\mathrm{E}$ and/or $\mathrm{F}$ postprandially, with the exception of $120 \mathrm{~min}$, which did not differ from baseline $(P<0.05)$. Reductions from baseline values were also observed in cats fed diets B and C at 300 and 360 min postprandially $(P<0.05)$.

When the AUC (Fig. 2) for each response profile in postprandial plasma P (Fig. 1) were determined, highest values were observed when cats were fed diet A $(P<0.001)$ compared with all other relevant diet exposures. Within each subset of diets, greater AUC values were observed when cats were fed diets A compared with $\mathrm{B}$ and $\mathrm{C}$, and diet $\mathrm{D}$ compared with $\mathrm{E}$ and $\mathrm{F}$, indicating an inverse relationship to Ca:P ratio level $(P<0.001$ for all). However, no significant differences were observed when cats were fed the diets containing the moderate compared with high Ca:P ratio (diets $\mathrm{B} v$. C and $\mathrm{E} v$. F, $P>0.05$ ). Across the diet subsets, AUC values were greater when cats were fed diets A $v$. $\mathrm{D}, \mathrm{B} v$. E and $\mathrm{C} v$. F $(P<0.001$ for all), suggesting a dose-dependent response to dietary STPP inclusion level. The mean AUC calculated for the postprandial plasma $\mathrm{P}$ responses to diets $\mathrm{E}$ and $\mathrm{F}$ were negative (Fig. 2).

\section{Effect of dietary inorganic phosphorus and calcium to phosphorus ratio on postprandial whole blood ionised calcium}

Postprandial blood iCa concentrations (Fig. 3) significantly decreased from baseline in all cats following intake of each diet $(P<0 \cdot 001)$. Diets A, D and E were also significantly lower than baseline concentrations at the final time point $(P<0.001$, $P=0.003$ and $P=0.001$, respectively). At $240 \mathrm{~min}$ post-meal, a significantly lower iCa level was observed in cats after the exposure to diet A compared with diets $\mathrm{C}$ and $\mathrm{D}(P<0 \cdot 001)$. Among diets with high STPP supplementation, significant decreases were observed at 240 and 300 min post-meal when cats were fed diet $\mathrm{A}$ with the low $\mathrm{Ca}: \mathrm{P}$ ratio compared with diet $\mathrm{C}$ with the high Ca:P ratio $(P<0 \cdot 001)$. Within the subset of diets with low STPP supplementation, an effect of Ca:P level was not observed $(P>0 \cdot 05)$.

When the AUC (Fig. 4) for each response profile in postprandial iCa (Fig. 3) were determined, the values calculated were negative due to the decreased postprandial iCa levels after the exposure to each diet compared with baseline. Diet A induced the largest AUC (A $v$. B $P=0.023$, A $v$. C $P<0.001$ and A $v$. D $P<0.001$, Fig. 4), while diet B had a significantly larger AUC than diet $\mathrm{E}(P=0 \cdot 027)$. 


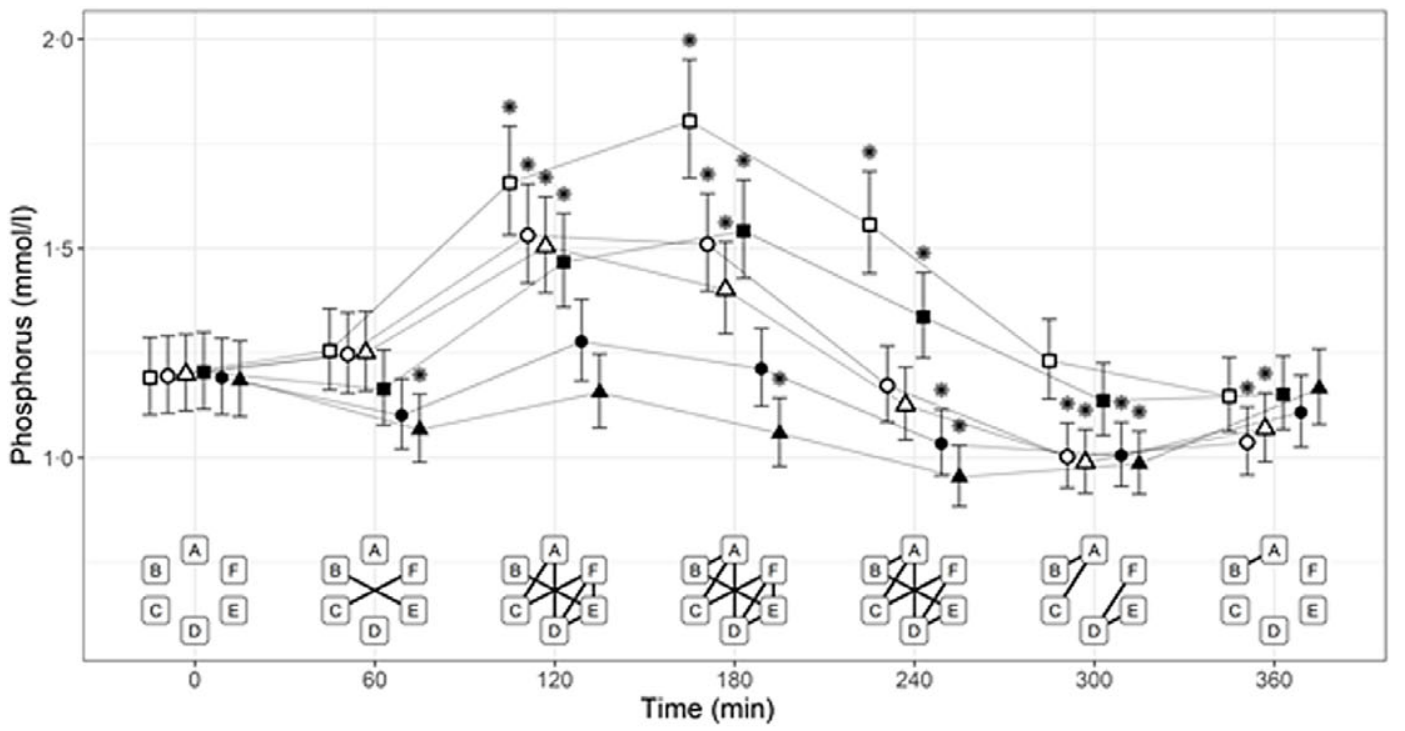

A: $1 \cdot 5 \mathrm{~g} / 1000 \mathrm{kcal}$ STPP $\mathrm{Ca}: \mathrm{P}=0.95$

- 8: $1 \cdot 5 \mathrm{~g} / 1000 \mathrm{kcal}$ STPP $\mathrm{Ca}: P=1 \cdot 62$

$\triangle \mathrm{C}: 1 \cdot 5 \mathrm{~g} / 1000 \mathrm{kcal}$ STPP $\mathrm{Ca}: \mathrm{P}=2 \cdot 18$ D: $0 \cdot 75 \mathrm{~g} / 1000 \mathrm{kcal}$ STPP,
Ca:P $=1 \cdot 11$

- E: $0.75 \mathrm{~g} / 1000 \mathrm{kcal}$ STPP. Ca: $P=1 \cdot 7$

A F: $0.75 \mathrm{~g} / 1000 \mathrm{kcal}$ STPP. $\mathrm{Ca}: \mathrm{P}=2.04$

Significant difference Between diets

Fig. 1. Mean plasma phosphorus ( $\mathrm{mmol} / \mathrm{l}$ ) concentrations over $360 \mathrm{~min}$ postprandial periods in cats following a meal of each experimental diet $\mathrm{A}-\mathrm{F}$ comprising $50 \%$ of the daily metabolisable energy requirement. *Significant differences to the baseline fasted sample (time 0 ); $P \leq 0.05$. The vertical bars for each mean indicates $95 \% \mathrm{Cl}$. STPP, sodium tripolyphosphate.

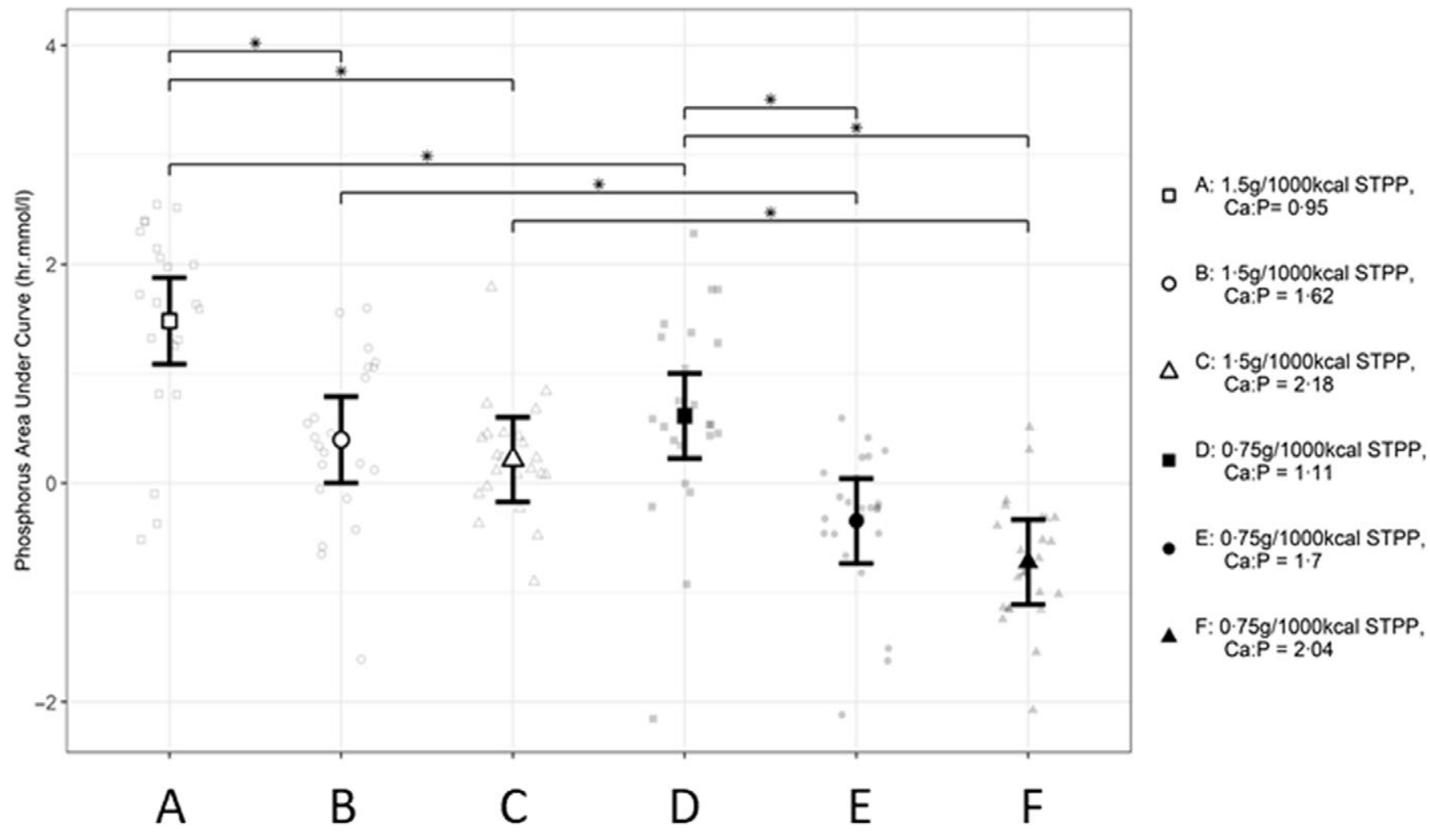

Fig. 2. Mean calculated AUC (h.mmol. $I^{-1}$ ) values for postprandial plasma $P$ responses in cats over 360 min periods following intake of a meal for each experimental diet A-F comprising $50 \%$ of daily metabolisable energy requirement (MER) *A significant difference between diet exposure responses; $P \leq 0.05$. The vertical bars for each mean indicates $95 \% \mathrm{Cl}$. STPP, sodium tripolyphosphate. 


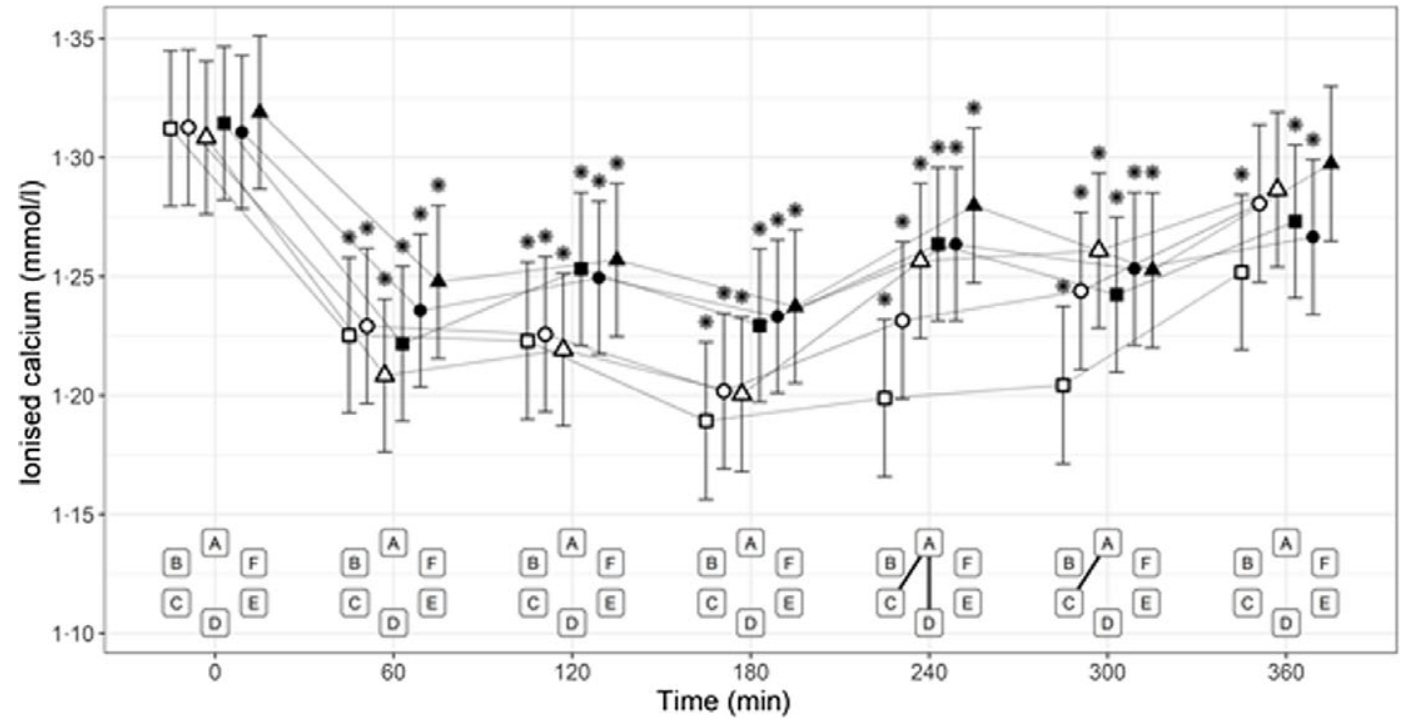

c A: $1.5 \mathrm{~g} / 1000 \mathrm{kcal}$ STPP, $\mathrm{Ca}: \mathrm{P}=0.95$

- B: $1 \cdot 5 g / 1000 \mathrm{kcal}$ STPP, $\mathrm{Ca}: P=1.62$

$\triangle \mathrm{C}: 1.5 \mathrm{~g} / 1000 \mathrm{kcal}$ STPP $\mathrm{Ca}: \mathrm{P}=2 \cdot 18$

- D: $0.75 \mathrm{~g} / 1000 \mathrm{kcal}$ STPP, $\mathrm{Ca}: \mathrm{P}=1 \cdot 11$

- E: $0.75 \mathrm{~g} / 1000 \mathrm{kcal}$ STPP. $\mathrm{Ca}: \mathrm{P}=1 \cdot 7$

A $\mathrm{F}: 0.75 \mathrm{~g} / 1000 \mathrm{kcal}$ STPP, Ca: $P=2.04$

Significant difference Between diets FALSE TRUE

Fig. 3. Mean whole blood ionised calcium ( $\mathrm{mmol} / \mathrm{l}$ ) concentrations over $360 \mathrm{~min}$ postprandial periods following intake of a meal for each experimental diet A-F comprising $50 \%$ of the daily metabolisable energy requirement (MER). ${ }^{*}$ Significant differences to the baseline fasted sample (time 0 ); $P \leq 0.05$. The vertical bars for each mean indicates $95 \% \mathrm{Cl}$. STPP, sodium tripolyphosphate.

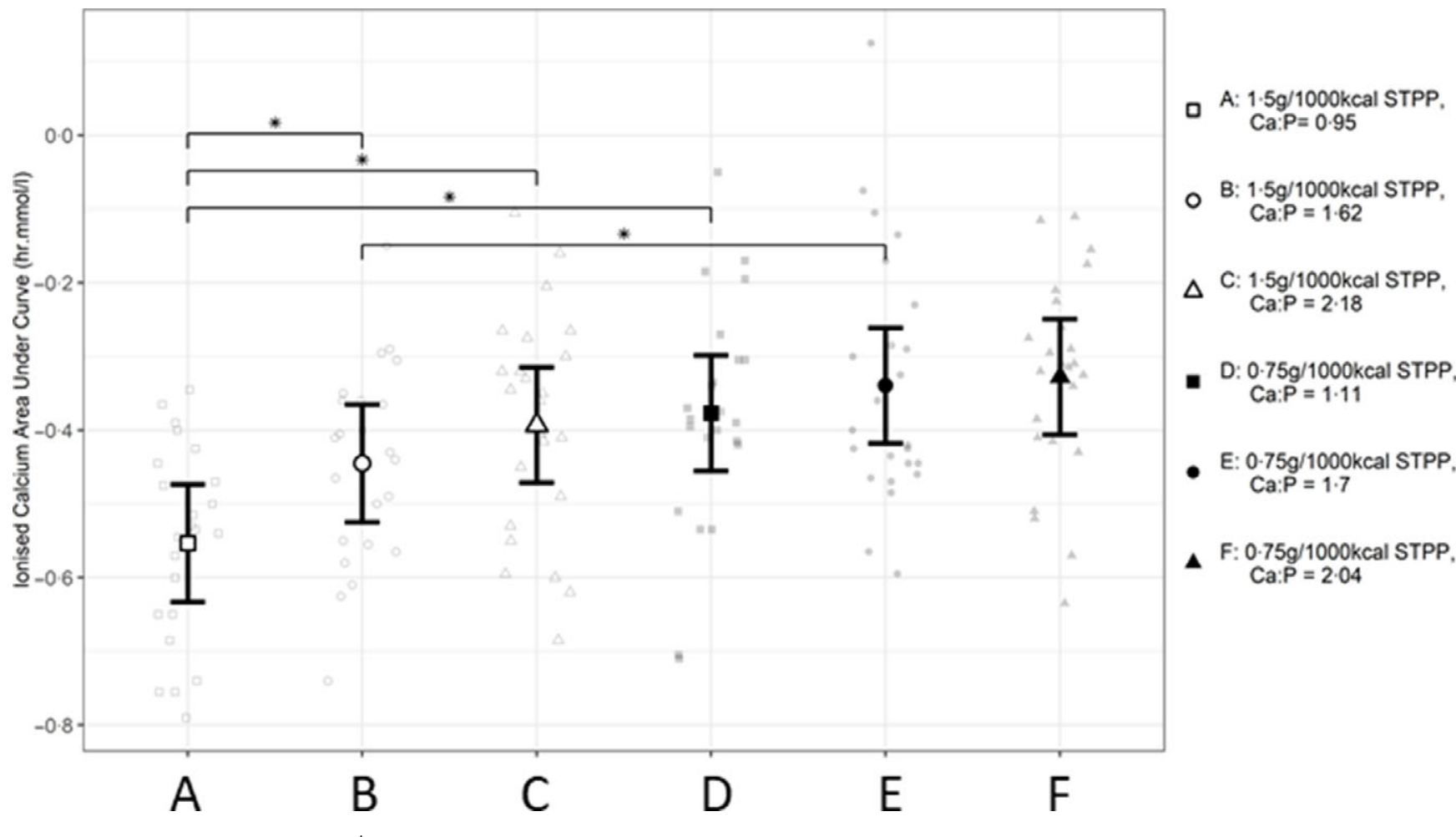

Fig. 4. Mean calculated AUC (h.mmol..$^{-1}$ ) values for postprandial whole blood ionised calcium responses in cats over 360 min periods following intake of a meal for each experimental diet A-F comprising $50 \%$ of the daily metabolisable energy requirement (MER). *Significant difference between diet exposure responses; $P \leq 0.05$. The vertical bars for each mean indicates $95 \% \mathrm{Cl}$. STPP, sodium tripolyphosphate. 


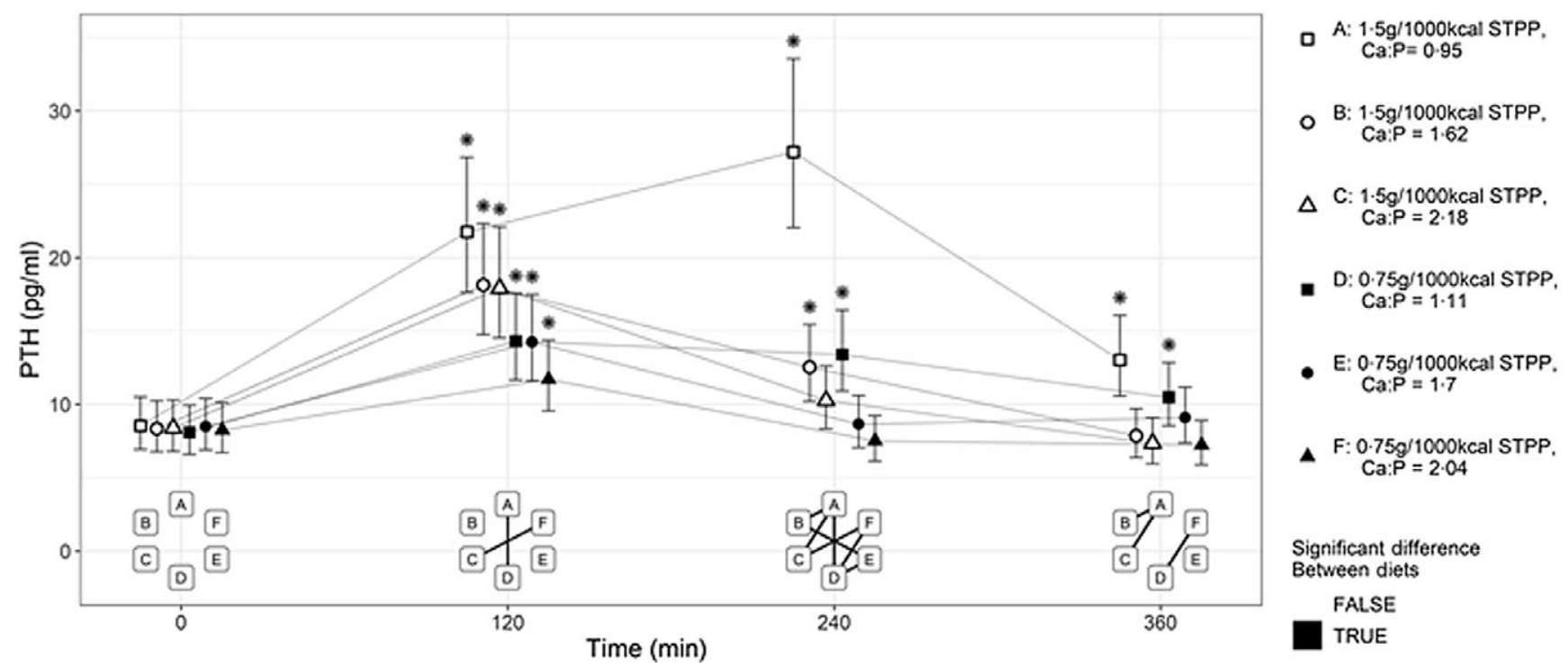

Fig. 5. Mean plasma parathyroid hormone (PTH, pg/ml) concentration over 360 min postprandial periods following intake of a meal for each experimental diet A-F comprising $50 \%$ of the daily metabolisable energy requirement (MER). *Significant difference to the baseline fasted sample (time 0 ); $P \leq 0.05$. The vertical bars for each mean indicates $95 \% \mathrm{Cl}$

Effect of dietary inorganic phosphorus and calcium to phosphorus ratio on postprandial plasma parathyroid hormone

Compared with baseline, all diets produced an increase in postprandial plasma PTH at $120 \mathrm{~min}(P<0 \cdot 05$, Fig. 5). The maxima in postprandial plasma PTH responses in cats (Fig. 5) differed, with the highest peak observed at 240 min after diet A intake compared with the other diets' lower peaks reached at $120 \mathrm{~min}$ ( $P<0.001$ for each comparison). At the lower STPP inclusion level, diet $\mathrm{D}$ exposure induced significantly higher values at 240 min compared with diets $\mathrm{E}$ and $\mathrm{F}$ with medium and high Ca:P, respectively $(P<0.001)$. The plasma PTH responses to diet A and diet $\mathrm{D}$ were still raised above baseline levels at $360 \mathrm{~min}$ following the meal $(P<0.001$ and $P=0.008$, respectively).

Within diet subsets of STPP supplementation, AUC values calculated for each response profile in postprandial PTH (Fig. 6) also indicated significant increases after diet A intake compared with diets $\mathrm{B}$ and $\mathrm{C}(P<0 \cdot 001)$, as well as between $\mathrm{D}$ and $\mathrm{F}$ $(P<0.001)$. There was no significant difference between diet $\mathrm{D}$ and $\mathrm{E}(P=0.083)$. Across diet subsets, dose-dependent responses to dietary STPP inclusion level were observed with significantly higher values observed following intake of diet A compared with D $(P<0 \cdot 001)$ with low Ca:P, diet B compared with $\mathrm{E}(P=0.01)$ with moderate $\mathrm{Ca}: \mathrm{P}$ and diet $\mathrm{C}$ compared with $\mathrm{F}(P<0.001)$ with high Ca:P.

\section{Discussion}

To better understand the role of dietary total Ca:P in P metabolism and regulatory (PTH) responses in the healthy, adult cat, a single-meal postprandial absorption kinetics model, as indicated by blood and plasma responses, was utilised. The data indicate that increasing dietary Ca:P from about 1.0 to between 1.6 and $2 \cdot 2$, reduced the peak and duration of both plasma $\mathrm{P}$ and $\mathrm{PTH}$ elevation in both subsets of diets containing two levels of STPP supplementation. The data support our previous observation that Ca:P ratio acutely affects P appearance in the plasma ${ }^{(4)}$, reflecting the gross changes observed in both apparent digestibility and urinary P excretion in other studies ${ }^{(11-15)}$. This finding adds further credence to the hypothesis that lower dietary Ca:P may be an additional factor in the development of reduced renal function and renal tissue changes reported in two long-term studies investigating the effects of dietary $\mathrm{P}$ levels in cats ${ }^{(2)}$. Furthermore, the level of soluble P salt supplementation (STPP) also significantly and dose-dependently affected postprandial $\mathrm{P}$, iCa and PTH responses, as previously reported ${ }^{(4)}$.

In other animal species, low dietary $\mathrm{Ca}: \mathrm{P}$ ratios have been associated with changes in $\mathrm{Ca}$ and $\mathrm{P}$ absorption, metabolism and regulation, as well as associated renal function and structure changes. Hoek et al. ${ }^{(27)}$ found that increasing total dietary Ca from $0.50 \%$ weight/weight, wt/wt) and decreasing Ca:P to 0.6 increased severity of nephrocalcinosis in rats when compared with a diet with a $\mathrm{Ca}: \mathrm{P}$ of 1.3 and a total $\mathrm{Ca}$ inclusion of $0 \cdot 25 \% \mathrm{wt} / \mathrm{wt}$. The rats with the most severe nephrocalcinosis also had higher urinary $\mathrm{P}$ excretion, whilst urinary Ca excretion was relatively stable and instead was eliminated from the body via the faeces ${ }^{(27)}$. This elimination of increased dietary $\mathrm{Ca}$ in the faeces has also been observed for cats ${ }^{(2,28)}$. In cats experiencing renal secondary hyperthyroidism, those assigned a dietary regimen involving phosphate restriction and a higher Ca:P (1.65 and 1.89, respectively) had reduced PTH and plasma P compared with cats assigned a maintenance diet $(\mathrm{Ca}: \mathrm{P}=1 \cdot 11)^{(29)}$. Paßlack et al ${ }^{(30)}$ increased dietary bone meal inclusion to produce diets with a Ca:P of $0 \cdot 76: 1$, 1.05:1 and 1.28:1, also resulting in increasing total $\mathrm{Ca}$ and $\mathrm{P}$ concentrations, in order to assess formation of uroliths in cats. Data showed that faecal elimination of $\mathrm{P}$ was increased when Ca:P was $1 \cdot 28: 1$, whilst urinary excretion (\% excretion by intake) and apparent digestibility of $\mathrm{P}$ were lowest on this 


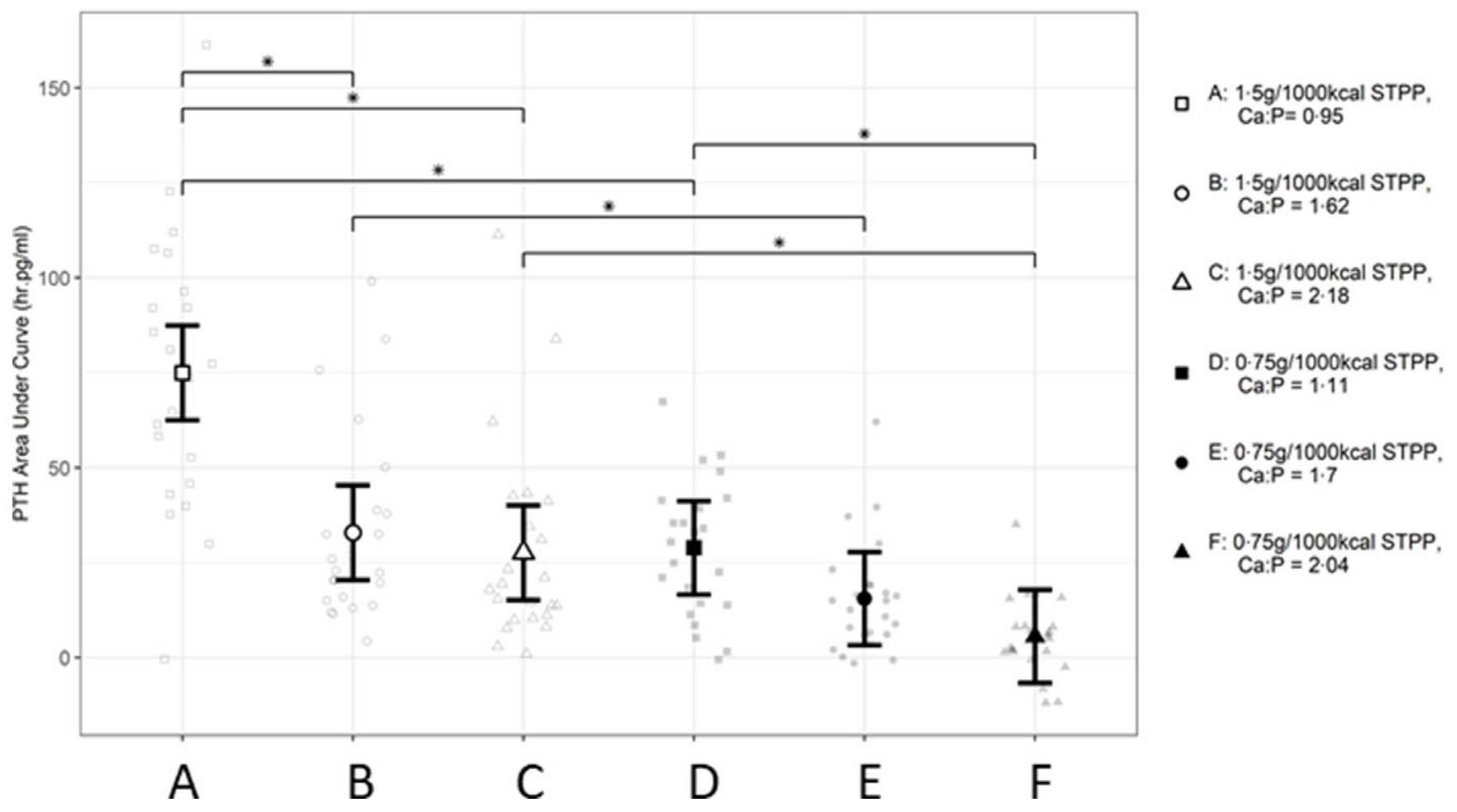

Fig. 6. Mean calculated AUC (h.mmol. $\left.\right|^{-1}$ ) values for postprandial plasma parathyroid hormone responses over 360 min periods following intake of a meal for each experimental diet A-F comprising $50 \%$ of the daily metabolisable energy requirement (MER). ${ }^{*}$ Significant difference between diet exposure responses; $P \leq 0.05$. The vertical bars for each mean indicate $95 \%$ CI. STPP, sodium tripolyphosphate, PTH, parathyroid hormone.

diet $^{(30)}$. Data also showed that urinary Ca excretion (\% excretion by intake) and PTH concentrations were significantly raised when the cats were fed the diet with $\mathrm{Ca}: \mathrm{P}$ of $0 \cdot 76: 1^{(30)}$. In a human study, Calvo et al. ${ }^{(31)}$ offered participants a test diet regimen with a mean Ca:P of $0 \cdot 25$ compared with a control regimen with a $\mathrm{Ca}: \mathrm{P}$ of 1.0 in the four meals eaten over the course of a day. This resulted in postprandial $\mathrm{P}$, iCa and PTH kinetics comparable to the data presented herein ${ }^{(31)}$. However, as this appears to be a cumulative effect following multiple meals, it is difficult to compare directly with our results following one meal.

For whole blood iCa, diet A caused the lowest iCa concentration at 240 and $300 \mathrm{~min}$ and highest PTH values at $240 \mathrm{~min}$. These data suggest that the reduction in whole blood iCa after the consumption of diet A may be associated with a homoeostatic up-regulation of PTH to a higher degree than for the other experimental diets in order to return iCa concentrations to baseline ${ }^{(32)}$. Similar findings were observed previously ${ }^{(4)}$, where the experimental diet associated with the lowest postprandial iCa and highest PTH also had a low Ca:P (0.6) and 3.5 $\mathrm{g} / 1000 \mathrm{kcal}(4184 \mathrm{~kJ}$ ) of highly soluble $\mathrm{P}$ in the form of sodium dihydrogen phosphate (SDHP, $\mathrm{NaH}_{2} \mathrm{PO}_{4}$ ). This may indicate that low dietary $\mathrm{Ca}: \mathrm{P}(<1)$ and a concomitant high inclusion of inorganic $\mathrm{P}(\geq 1.5 \mathrm{~g} / 1000 \mathrm{kcal}(4184 \mathrm{~kJ}))$ causes a larger response in PTH to regulate iCa concentrations. This may help explain the adverse effects to renal health seen in cats following 4 weeks of exposure to such a diet in Alexander et al. ${ }^{(2)}$. Decreased iCa and/or increased serum $P$ over prolonged periods have been linked to increased PTH concentrations and parathyroid dysfunction in humans ${ }^{(33)}$. It should be noted that the dietary $\mathrm{Ca}$ of the experimental diets did differ, with diets A-C having a lower content than their respective counterparts (D-F). A study in humans found that a high Ca, high vitamin D breakfast increased iCa postprandially compared with a low Ca, low vitamin D breakfast ${ }^{(34)}$. This study did not find any significant difference in PTH postprandially between the $\operatorname{diets}^{(34)}$

Significantly higher, dose-dependent changes in plasma $\mathrm{P}$ and PTH concentrations were observed after the intake of diets with increasing STPP inclusion in this and previous studies ${ }^{(4)}$. The data from the current study also indicate an interactive effect of STPP inclusion level with total dietary Ca:P ratios, with increasing Ca:P to moderate ( about 1.5) or high ( about 2) values apparently leading to decreased appearance of $\mathrm{P}$ in the plasma following a meal at both STPP inclusion levels when compared with low dietary Ca:P ( about 1). The magnitude of peak postprandial plasma $\mathrm{P}$ concentrations following diet $\mathrm{D}$ intake (low STPP, low Ca:P) was similar to those after the intake of diets B and C (high STPP and moderate and high Ca:P, respectively), resulting in similar AUC. However, the maximum value reached following intake of both diets A and D, with Ca:P ratios of about 1 but differing in STPP inclusion, was at $180 \mathrm{~min} v .120 \mathrm{~min}$ following intake of all the other diets with higher Ca:P ratios. Thus, these data indicate that the observed effect of diets including a soluble $\mathrm{P}$ salt in the form of STPP, which raised plasma $\mathrm{P}$ and PTH concentrations, could be moderated by increasing the dietary Ca:P between about 1.5 and $2 \cdot 0$. This could mean that adjustments in total $\mathrm{Ca}: \mathrm{P}$ ratio to $\geq 1.6$ in dietary formulations 
may aid in ameliorating increases in plasma $\mathrm{P}$ and PTH. This hypothesis is supported by the results from a recent 7-month feeding trial in cats testing STPP inclusion levels providing an inorganic P level of $1.0 \mathrm{~g} / 1000 \mathrm{kcal}(4184 \mathrm{~kJ})$, but with two different total $\mathrm{P}$ and $\mathrm{Ca}: \mathrm{P}$ ratios ${ }^{(35)}$. Although a no-observed-adverseeffect level was observed, cats fed the diet with the lower total $\mathrm{P}$ and Ca:P ratio showed some increases in measures related to $\mathrm{Ca}$ and $\mathrm{P}$ metabolism, namely urinary excretion of $\mathrm{P}$ and plasma FGF-23 concentration, that were not found in cats fed the diet with the higher total $\mathrm{P}$ and higher $\mathrm{Ca}: \mathrm{P}$ ratio ${ }^{(35)}$.

When comparing diets with similar formulations across this study with previous acute ${ }^{(4)}$ and chronic exposure ${ }^{(2)}$ studies, some differences in responses were observed. Despite similar dietary total and soluble $\mathrm{P}$ levels and $\mathrm{Ca}: \mathrm{P}$ ratios, results reported in our previous study ${ }^{(4)}$ showed a lower postprandial maximum of $1.57 \mathrm{mmol} / \mathrm{l}$ in plasma $\mathrm{P}$ that did not return to baseline by 360 min post-feeding. In addition, no postprandial PTH peak was observed with levels not differing from baseline within the $360-$ min postprandial period. And yet when that $\operatorname{diet}^{(4)}$ was fed to cats for 28 weeks, development of renoliths and structural changes in the kidneys were observed in a number of cats ${ }^{(2,4)}$. The formulation of the two diets in the current compared with previous studies ${ }^{(2,4)}$ differed slightly, however, and this suggests that there are several other diet-related factors that could affect the postprandial levels of P and PTH in the plasma of cats following a meal. These factors could include differences in the production technology and diet format, the raw materials and ingredients used, fibre content, other minerals, base excess and vitamin D concentration. Data from cats, fed various cellulose fibre lengths, showed that increased dietary crude fibre content may increase $\mathrm{Ca}, \mathrm{P}$ and $\mathrm{Mg}$ excretion, leading to lower absorption $^{(36)}$. Dietary fibre may also change the $\mathrm{pH}$ of the ileal digesta, increasing $\mathrm{Ca}$ absorption thus possibly leading to a reduced availability to form insoluble $\mathrm{Ca}-\mathrm{Mg}-\mathrm{P}$ complexes in the intestine, thereby indirectly affecting $\mathrm{P}$ absorption ${ }^{(15)}$. Commercially relevant diet formulations rely on varying combinations of raw materials to reach desired nutrient compositions. These raw materials can vary in nutrient profile from batch to batch $^{(37)}$ and therefore cause unintended differences between the experimental diets. However, the current study used wet format diets, and raw materials are unlikely to contain significant phytate or fibre sources. If the raw materials did contain these fibre sources, diets A-C should have followed the same pattern as diets D-F; therefore, the unexpectedly high crude fibre content of $\mathrm{F}$ cannot be accounted for. A point to note is that any potential analytical error in crude fibre would also lead to an underestimation of the PME of the diet, leading to (1) an overestimation of $\mathrm{P}$ in $\mathrm{g} / 1000 \mathrm{kcal}$ ( $4184 \mathrm{~kJ}$ ) for diet F, and (2) overfeeding the cats diet $\mathrm{F}$ relative to the diets A-E. These factors should be taken into account when reviewing the data. Despite this uncertainty, the findings are more relevant to commercial formulations than employing semi-purified diet formats where nutrient digestibility is significantly greater. The diets formulated for this study increased in base excess with increasing dietary Ca:P, which limits our ability to separate out the two factors and should therefore be a consideration for future studies. Vitamin D is linked to increased P absorption in cats ${ }^{(38)}$ and, although attempts to maintain concentrations were successful for the most part, the higher vitamin D content in the current diet A may have led to the higher peak in plasma $\mathrm{P}$ compared with the more prolonged but smaller postprandial increases in plasma P observed previously ${ }^{(4)}$. Diet format may also alter the absorption rate of minerals and affect plasma $P$ postprandial kinetic profiles, likely linked to differences in raw ingredients and often higher fibre content in dry $v$. wet diets as described above. Previous investigation of the postprandial plasma $\mathrm{P}$ kinetics of two dry format diets, one containing SDHP and the other STPP, showed no significant differences in peak height and duration of plasma P; however, the AUC was significantly higher in the SDHP $\operatorname{diet}^{(4)}$. SDHP has a higher water solubility than STPP $(800 \mathrm{~g} / \mathrm{l} \text { and } 150 \mathrm{~g} / \mathrm{l} \text {, respectively })^{(39)}$ most likely contributing to the AUC data differences. Renal P excretion has also been found to be increased in cats fed a diet with sodium monophosphate compared to cats fed a diet containing calcium monophosphate $^{(10)}$. These data may suggest that there are differences in absorption between added phosphorus salts that warrants further attention. The use of a wet and dry commercial diet rotation, which is part of the cats' normal care routine, between experimental trials may have influenced the outcome of the trial due to the potential for exposure to different dietary vitamin D and mineral contents, possibly altering the homoeostatic capacity of $\mathrm{PTH}^{(31,40)}$. There were no observed differences in baseline (fasted) values of plasma P, PTH or whole blood iCa between exposures to the experimental diets. This suggests that the randomisation of the experimental diets fed coupled with the 18-h fast and the crossover design may have limited variation between fasted values. However, a potential impact of the dietary regimen between sampling periods cannot be completely discounted.

While there are still some unknowns around the possible contributions of other dietary factors, such as added soluble $\mathrm{P}$ source, our previously reported data indicate a contributory role of a low Ca:P of less than 1.0 in the adverse effects reported when single-batch experimental diets were fed to healthy adult cats for a minimum of 4 weeks ${ }^{(2)}$. Our previous data indicate that this effect may already be seen at a ratio of $1 \cdot 5$. However, identifying the role of dietary Ca:P was not the goal of those studies ${ }^{(4)}$. The preliminary findings here suggest that the effects of dietary soluble P source STPP on plasma P and PTH concentrations can be mitigated by increasing the Ca:P ratio to 1.6 and above, as well as by reducing the level of added soluble $\mathrm{P}$ in the diet. These factors should be a consideration for formulation of feline diets in the future and would further benefit from longer-term feeding trials, including measures of renal function, to verify.

\section{Acknowledgements}

The authors would like to acknowledge the skills and expertise of colleagues at Waltham in the care, training and sampling of the cats and for the analysis of samples collected throughout the studies. The authors recognise the contribution of Jonathan Elliott and Anna Riddle (The Royal Veterinary College, London) in the analysis of the PTH samples.

This work was funded by Mars Petcare. The Waltham ${ }^{\circledR}$ Petcare Science Institute is a fundamental research centre for Mars Petcare. 
J. C. C., J. R., J. A., V. B., D. W. L., R. B., P. W. and A. M. B. conceived the project. J. C. C., M. G., J. R., D. W. L., R. B., P. W. and A. M. B. developed the overall research plan and had study oversight. J. C. C. and M. G. conducted the research and oversaw the analysis of the samples. R. S. and A. C. performed the statistical analysis. J. C. C. authored the paper with J. E. A., J. R., D. L., R. B., P. W. and A. M. B.

J. C. C., R. S., A. C., M. G., J. R., J. A., D. L., R. B., P. W. and A. M. B. were employees of Mars Petcare during the study.

\section{Supplementary material}

For supplementary material/s referred to in this article, please visit https://doi.org/10.1017/S000711452100461X

\section{References}

1. Marino CL, Lascelles BD, Vaden SL, et al. (2014) Prevalence and classification of chronic kidney disease in cats randomly selected from four age groups and in cats recruited for degenerative joint disease studies. J Feline Med Surg 16, 465-472.

2. Alexander J, Stockman J, Atwal J, et al. (2019) Effects of the long-term feeding of diets enriched with inorganic phosphorus on the adult feline kidney and phosphorus metabolism. Br J Nutr 121, 249-269.

3. Dobenecker B, Webel A, Reese S, et al. (2017) Effect of a high phosphorus diet on indicators of renal health in cats. J Feline Med Surg 20, 339-343.

4. Coltherd JC, Staunton R, Colyer A, et al. (2019) Not all forms of dietary phosphorus are equal: an evaluation of postprandial phosphorus concentrations in the plasma of the cat. $\mathrm{Br} J$ Nutr 121, 270-284.

5. Finch NC, Syme HM \& Elliott J (2012) Parathyroid hormone concentration in geriatric cats with various degrees of renal function. J Am Vet Med Assoc 241, 1326-1335.

6. Geddes RF, Finch NC, Syme HM, et al. (2013) The role of phosphorus in the pathophysiology of chronic kidney disease. J Vet Emergency Crit Care 23, 122-133.

7. Berndt T \& Kumar R (2009) Novel mechanisms in the regulation of phosphorus homeostasis. Physiology 24, 17-25.

8. Cupisti A \& Kalantar-Zadeh K (2013) Management of natural and added dietary phosphorus burden in kidney disease. Semin Nephrol 33, 180-190.

9. Isakova T, Gutiérrez OM, Smith K, et al. (2011) Pilot study of dietary phosphorus restriction and phosphorus binders to target fibroblast growth factor 23 in patients with chronic kidney disease. Nephrol Dialysis Transplant 26, 584-591.

10. Dobenecker B, Hertel-Böhnke P, Webel A, et al. (2018) Renal phosphorus excretion in adult healthy cats after the intake of high phosphorus diets with either calcium monophosphate or sodium monophosphate. J Animal Physiol Animal Nutr 102, 1759-1765.

11. Kienzle E, Pessinger C \& Thielen C (1998) Phosphorous requirements of adult cats. J Animal Physiol Animal Nutr 80, 90-100.

12. Kienzle E, Thielen C \& Pessinger C (1998) Investigations on phosphorus requirements of adult cats. J Nutr 128, 2598s-2600s.

13. Mack JK, Alexander LG, Morris PJ, et al. (2015) Demonstration of uniformity of calcium absorption in adult dogs and cats. J Anim Physiol Anim Nutr 99, 801-809.

14. Pastoor FJ, Opitz R, Van't Klooster AT, et al. (1994) Dietary calcium chloride $v$. calcium carbonate reduces urinary $\mathrm{pH}$ and phosphorus concentration, improves bone mineralization and depresses kidney calcium level in cats. J Nutr 124, 2212-2222.

15. Pastoor FJ, Van't Klooster AT, Mathot JN, et al. (1994) Increasing calcium intakes lower urinary concentrations of phosphorus and magnesium in adult ovariectomized cats. J Nutr 124, 299-304.

16. FEDIAF (2019) Nutritional Guidelines for Complete and Complementary Pet Food for Cats and Dogs. March 2019. FEDIAF, The European Pet Food Industry. www.fediaf.org/ self-regulation/nutrition

17. Böswald LF, Dobenecker B, Clauss M, et al. (2018) A comparative meta-analysis on the relationship of faecal calcium and phosphorus excretion in mammals. J Anim Physiol Anim Nutr 102, 370-379.

18. Pastoor FJ, Van't Klooster AT, Opitz R, et al. (1995) Effect of dietary magnesium level on urinary and faecal excretion of calcium, magnesium and phosphorus in adult, ovariectomized cats. BrJ Nutr 74, 77-84.

19. Bjornvad CR, Nielsen DH, Armstrong PJ, et al. (2011) Evaluation of a nine-point body condition scoring system in physically inactive pet cats. Am J Vet Res 72, 433-437.

20. de Brito Galvão JF, Schenck PA \& Chew DJ (2017) A quick reference on hypercalcemia. Vet Clin North Am Small Anim Pract 47, 241-248.

21. Geddes RF, Finch NC, Elliott J, et al. (2013) Fibroblast growth factor 23 in feline chronic kidney disease. J Vet Intern Med 27, 234-241.

22. Williams T, Elliott J \& Syme H (2012) Calcium and phosphate homeostasis in hyperthyroid cats-associations with development of azotaemia and survival time. J Small Anim Pract 53, 561-571.

23. R Development Core Team (2017) R: a Language and Environment for Statistical Computing. http://web.mit.edu/r_ v3.4.1/fullrefman.pdf

24. Bates D, Mächler M, Bolker B, et al. (2015) Fitting linear mixedeffects models using lme4.J Stat Softw 2015, 48.

25. Hothorn T, Bretz F \& Westfall P (2008) Simultaneous inference in general parametric models. Biometrical J 50, 346-363.

26. Wickham H (2009) Ggplot2: Elegant Graphics for Data Analysis. https://ggplot2-book.org/index.html

27. Hoek AC, Lemmens AG, Mullink JWMA, et al. (1988) Influence of dietary calcium:phosphorus ratio on mineral excretion and nephrocalcinosis in female rats. $J$ Nutr $\mathbf{1 1 8}$, 1210-1216.

28. Paßlack N, Schmiedchen B, Raila J, et al. (2016) Impact of increasing dietary calcium levels on calcium excretion and vitamin D metabolites in the blood of healthy adult cats. PLOS ONE 11, e0149190.

29. Barber PJ, Rawlings JM, Markwell PJ, et al. (1999) Effect of dietary phosphate restriction on renal secondary hyperparathyroidism in the cat. I Small Anim Pract 40, 62-70.

30. Passlack N \& Zentek J (2013) Urinary calcium and oxalate excretion in healthy adult cats are not affected by increasing dietary levels of bone meal in a canned diet. PLOS ONE $\mathbf{8}$, e70530.

31. Calvo MS, Kumar R \& Heath H (1988) Elevated secretion and action of serum parathyroid hormone in young adults consuming high phosphorus, low calcium diets assembled from common foods. J Clin Endocrinol Metab 66, 823-829.

32. Shaker JL \& Deftos L (2018) Calcium and Phosphate Homeostasis. Endotext. South Dartmouth, MA: MDText.com, Inc.

33. Silver J \& Levi R (2005) Regulation of PTH synthesis and secretion relevant to the management of secondary 
hyperparathyroidism in chronic kidney disease. Kidney Int $\mathbf{6 7}$, S8-S12.

34. Soares M \& Ping-Delfos WCS (2008) Second meal effects of dietary calcium and vitamin D. Eur J Clin Nutr 62, 872-878.

35. Coltherd JC, Alexander JE, Pink C, et al. (2021) Towards establishing no observed adverse effect levels (NOAEL) for different sources of dietary phosphorus in feline adult diets: results from a 7-month feeding study. Br J Nutr 126, 1626-1641.

36. Prola L, Dobenecker B, Mussa PP, et al. (2010) Influence of cellulose fibre length on faecal quality, mineral excretion and nutrient digestibility in cat. J Animal Physiol Animal Nutr 94, 362-367.

37. Rivera JA, Sebranek JG, Rust RE, et al. (2000) Composition and protein fractions of different meat by-products used for petfood compared with mechanically separated chicken (MSC). Meat Sci 55, 53-59.

38. Chacar FC, Kogika MM, Zafalon RV, et al. (2020) Vitamin d metabolism and its role in mineral and bone disorders in chronic kidney disease in humans, dogs and cats. Metabolites 10, 499.

39. Lampila LE (2013) Applications and functions of food-grade phosphates. Ann NY Acad Sci 1301, 37-44.

40. Littledike ET \& Goff J (1987) Interactions of calcium, phosphorus, magnesium and vitamin $\mathrm{D}$ that influence their status in domestic meat animals. J Anim Sci 65, 1727-1743.

41. Jeremias JT, Nogueira SP, Brunetto MA, et al. (2013) Predictive formulas for food base excess and urine $\mathrm{pH}$ estimations of cats. Anim Feed Sci Technol 182, 82-92. 